\title{
EDITORIAL
}

\section{LA REVISTA ESPAÑOLA DE SALUD PÚBLICA: UNA OCTOGENARIA CON MUY BUENA SALUD}

\author{
Cristina Pérez Andrés \\ Comité de redacción de la Revista Española de Salud Pública. Ministerio de Sanidad y Consumo.
}

A finales del próximo mes de diciembre hará once años que me hice cargo de la redacción de la Revista de sanidad e higiene pública. Coincidiendo con ello pasó a llamarse Revista Española de Salud Pública, cambiando también su imagen exterior, lo que provocó no pocas voces en contra, sobre todo por parte de los miembros del comité científico que, con razón, protestaron por no haber podido opinar.

Otros cambios importantes iban a producirse durante estos años, ya que la difusión del uso de internet y del correo electrónico han posibilitado un hacer muy dinámico en la redacción de la revista, la creación de una página web y un contacto directo con las personas que forman parte del comité científico, con las que escriben los trabajos y con las que los evalúan.

A lo largo de estos once años la Revista, gracias al buen hacer de las personas que me precedieron en la redacción, ya estaba en las principales bases de datos nacionales e internacionales de revistas científicas, ha sido incluida en los diferentes sitios web y bibliotecas virtuales que con el desarrollo de internet se han ido creando, por lo que el acceso a su contenido es hoy posible desde cualquier lugar del mundo con conexión a la red. En el año 2001 se hizo además un Cdrom que contiene todos los ejemplares de la revista desde 1991 al 2000, ambos inclui- dos, y espero que pronto podamos hacer el segundo porque, como bien preocupa en la Unesco, la información que existe en forma electrónica puede perderse si no se establecen los mecanismos oportunos. La conservación de la información de las páginas web también plantea problemas, ya que su contenido varía incluso a diario y hay que idear soluciones que posibiliten la perdurabilidad de los documentos publicados con estos medios. Ello es también, en mi opinión, una de las razones por las que la edición impresa de las revistas no debería desaparecer.

La edición electrónica de las revistas científicas y el movimiento para su acceso abierto (open acces), que tan buena acogida está teniendo entre las personas que publican y evalúan trabajos científicos, son una muy buena oportunidad para que parte de las desigualdades sociales terminen, al menos las que se deben a la falta de recursos materiales para acceder a la lectura de los resultados de las investigaciones científicas.

El contacto directo con las personas que forman parte del comité científico de la Revista española de salud pública ha permitido la publicación de este número que conmemora su buena salud, manifestada en un octogésimo cumpleaños caracterizado por el vigor y las ganas de trabajar en cantidad y con calidad. 
La imposibilidad de hacer un número en el que participaran todos los miembros del comité científico impuso la elección de las personas más veteranas en él, pero debemos tener presente que no están todas las que son. Algunas de las que aceptaron participar no lo han hecho finalmente por falta de tiempo. No importa. La revista va a seguir cumpliendo años y vamos a seguir celebrándolos como se merece.

También participan en este número las sociedades científicas relacionadas con la salud pública y consecuencia de ello son los trabajos en los que colaboran Ildefonso Hernández, presidente de la Sociedad Española de Epidemiología, Jose Ramón Repullo y Andreu Segura, presidente y vicepresidente de Sespas, y el de Vicente Ortún y Ricard Meneu, quienes colaboran como representantes de la Asociación de Economía para la Salud.

Muchas gracias a todas las personas que habéis dedicado parte de vuestras vacaciones de verano para que los trabajos estuvieran terminados a tiempo. Muchas gracias muy especialmente a Gerardo Clavero, a quien se le pidió colaborar a última hora y lo ha hecho con la rapidez de un chaval. Y muchas felicidades a la revista, a las personas que pensáis en ella cuando tenéis un trabajo para publicar, a las que los evaluáis, y a las que los leéis. Sois para la revista afortunadamente imprescindibles. 